\title{
Gamification in Proprietary Innovation: Identifying a Technical Framework Based on Patent Data.
}

\author{
Patrick J. Höflinger \\ Technische Universität München \\ p.hoeflinger@tum.de
}

\begin{abstract}
This paper reveals dominant patterns of gamification in proprietary innovation and develops a technical framework. In recent years, a rash increase in securitizing gamification-related inventions has taken place. By analyzing the content of 134 unique patents from USPTO and EPO with an in-depth raw data text analysis, the technical background is explored holistically. To discover meaningful patterns and thus to derive implications from the patent data they are visually summarized. Especially predominant are the topics of device, data, user and game. Based on the nature of the data, being evidence-based and future directed, our technical framework integrates these patterns and sets it into relation. An additional analysis provides further insights into fundamental game elements. As patents serve as a decisive indicator of future product introductions, the information gathered in this paper represents essential strategic information to guide practitioners and researchers in the area of gamification.
\end{abstract}

Keywords: Gamification, Patents, Technology, Patterns, Technology Analysis.

\section{Introduction}

Over the past years, scholarly and likewise practical interest in gamification strongly increased [35]. Numerous publications and novel applications indicate an ongoing momentum. Likewise, the current state of gamification research indicates a diverse nature of the field, ranging from education, humancomputer interaction or health [62]. Based on recent research it has been found that technological innovation in this field is fragmented [33]. A large number of patents (e.g. US8768751, US8821272, EP2689360) have gamification incorporated as a part of their novelty, yet spread across multiple technological domains. However, none of the current studies analyses how this "trend" is actually implemented in patents based on its actual content to build a technical framework thereon. It is unclear what kind of gamification-related technical components exist and what creates a novel solution that is the first of its kind. To consolidate and strengthen the technology-related side we take a patent perspective.

A previous paper analyzed technology classes, firms and preliminary value indicators in gamification related patents [33]. That is standard bibliometric information that automatically comes with the patent document from the patent office (e.g. applicants, IPC classes, citations and so forth). Since then about 60 new patents have been filed indicating rapid growth (c. $90 \%$ increase in 6 months). A rash increase in applications is often seen as a signal of technology emergence and industry acceptance [21], requiring constant analysis. Securitizing proprietary innovation is only fostered when technologies are likely to become economically valuable [21].

We study patents and its content out of the following reasoning. First, patent data in general is one of the most relevant measures of innovation [23, 32]. Patents are one of the few real indicators of future product releases, revealing precise technical information long before inventions reach the marketplace [66]. Usually innovative products new to markets are often protected by patents [3], therewith incentivizing costly research and development [2]. Beneficially, it is public information, covers a comprehensive set of technologies in a standardized manner and is available for an extensive time period [54]. The text itself represents codified knowledge, meaning that the description of a certain technology is objective and tangible [12]. Therefore, we advance on what the gamification related patents are actually about in an in-depth structural and content-based analysis. Especially in emerging fields, identifying such trends via patents serves as technological forecasting [7, 54], to identify opportunities of new technology [18] and to conduct competitive analysis [52]. This analysis is useful as any action in IP is essentially based on the purpose to securitize precise technical information to withstand competition.

Second, since the field of gamification related patents is fragmented [33] we integrate and synthesize current proprietary knowledge. Based on a review of empirical studies, not all applications just become better per se through a gamified design [28]. Above, the context influences the application of gamification [59]. None of the studies in gamification focused on its technical foundations to create a framework despite the increased patent filings (e.g. US8768751, EP2689360). Therewith, this paper is able to determine connected patterns of gamification related technology, i.e. technical foundations and functionalities. The integration of gamification into a 
framework is a necessary step forward to deepen our holistic understanding via mapping and visualization. Such analysis of all gamification-related patents in a new dataset represents a utile approach for its technical and contextual positioning. Uncovering patterns, structures and relations of proprietary knowledge provides valuable information for the understanding of gamification.

To do so, we begin by reviewing the foundations that have been applied to studying the phenomenon. Second, we use an analytical approach to identify relevant patents. Third, based on identified patents we cluster and distinguish them into a framework. Finally, our analyses are critically discussed with additional limitations and options for future research.

\section{Theory}

\subsection{Gamification}

Gamification is ,a process of enhancing a service with affordances for gameful experiences in order to support users' overall value creation" [35] and is increasingly used as a method to stimulate motivation and engagement [62]. Components such as levels, points or rewards that are usually applied in traditional games are used in new ways [29]. Since its first introduction by Deterding, Khaled, Nacke and Dixon [20] and Huotari and Hamari [34] various papers in different contexts center around its use as a new incentive system such as cost engineering [74], mobile apps [73], education [26] or personalized health [50]. However, Gamification itself has to be differentiated from real games or "serious games" as it does not include traditional gameplay [20]. The successfulness of gamification essentially depends on its design in relation to the area of application [69].

\subsection{Patents}

Patents are a temporary and legal monopoly for the commercialization of inventions [27]. To get them granted by the patent office (e.g. USPTO or EPO), the application itself needs to be the first of its kind ("novelty"), second a nontrivial extension of what is known and finally useful thus having commercial potential $[27,51]$. After the examination by the patent office, a public document is provided with detailed information about the invention [27]. Often, these documents specifically indicate technical details for future product releases long before actual market introductions [66]. Each new patent is a kind of a "bet" about a particular technology that someday may become economically relevant [21]. Otherwise, the economic payoff for engineering, time, capital and legal investments into filing a certain invention would not be given. This is why patents are a useful tool to monitor technological developments of rather early stage concepts as gamification and its various applications. Especially for firms, patents are an essential part of their core business as a strategic tool to protect against imitation and likewise to block competitors [8].

\subsection{Examples of gamification related patents}

To give insights of how gamification has been used, we highlight two patents from different domains. An example is SAP AG's patent "Gamification for Enterprise Architectures" (US20140051506A1). Herein, gamification plays a vital role in governing and managing enterprise information systems. The gamification rules \& mechanics "may incorporate policies and procedures (whether internally developed or externally imposed) that govern various operations". These rules are either originated as the system analyzes behavior of users and reacts (e.g. based on events) by triggering responses. The system itself is flexible and can consist of various information systems. In Figure 1, we have attached a part of the original patent document to show its relations (note: Figure 4 and $4 \mathrm{a}$ of the original patent document).

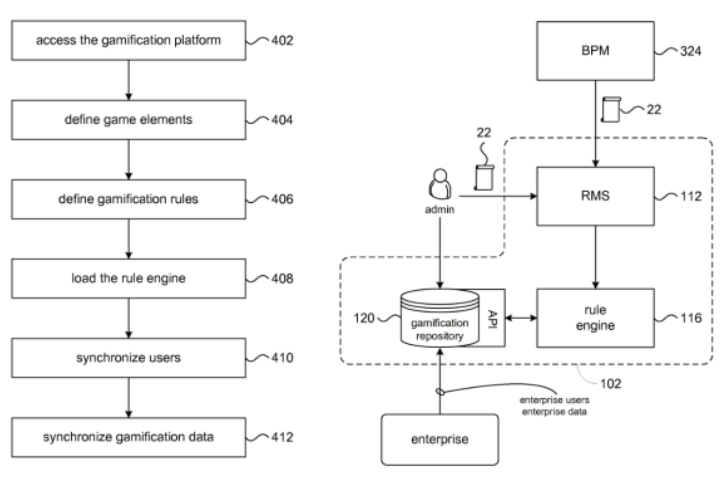

Figure 1. SAP AG example of patent document.

Another example would be General Electric's patent "Methods and systems for improving patient engagement via medical avatars" to improve electric patient care and support (US20160045171A1). Therein, the patient can see a three-dimensional virtual avatar of its own anatomy for information purposes. Gamification comes into play as the patient can be encouraged and/or challenged via e.g. social games that are specific to the disease and the patient's treatment plan (see Figure 2). Based on a game plan the medical avatar challenges, educates, coaches and alerts the patient thereby facilitating the interaction.

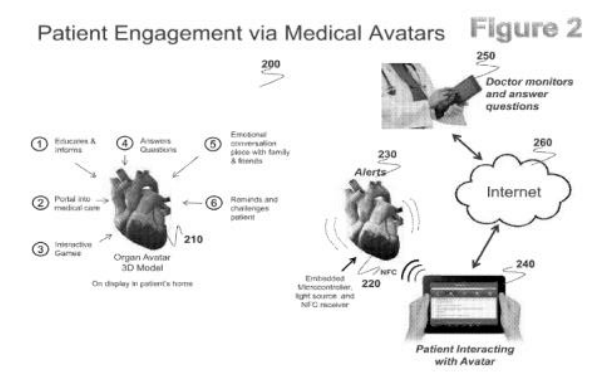

Figure 2. GE example of patent document. 


\subsection{Technology monitoring with patent data}

Technology is constantly evolving and its advancement is a major force for economic growth [6, 36]. Using and applying concrete practical information to analyze technology is a decisive task for corporations to keep up with technological trends to monitor innovation [38]. Hence, identifying new technology opportunities and monitoring its innovation patterns has become an essential part for organizational strategy and serves therewith as a driver for firm growth and success [49]. Logically, the decision to do a certain investment in a technology should be based on the right and meaningful sources [1], finally to prioritize R\&D investment [31].

Within the different forms of investigation for innovative output [17], patent analyses have become one of the main sources to track technological innovation [38]. Patents serve as an objective indicator [15] and have are a reliable state-of-the-art indicator of inventive developments in modern technology [72]. The investigation of such information does help to evaluate a technology's originality and its progressiveness [42]. Several methods for patent forecasting in various domains have been developed in recent years [see 1,46]. Yet, these analyses are complex and time-consuming for R\&D managers [53] in times where processes become complex, innovation cycles shorten and demand is volatile [71].

Recently, there is a increased interest to use text mining techniques in various research areas [40, 45], such as new technology creation [46] or new product development [44]. Such methods decrease human efforts to analyze rich amounts of unstructured text data [65]. A process which extracts previously unknown information in a form which can be comprehended, acted upon and finally used for decisions processes is essential to support technology management [48]. They uncover not only technical niches but also uncovered sectors [5]. Patent visualization methods are considered to be a relevant tool as their results are often regarded as superior to conventional techniques $[14,70]$. For example, the Japan Patent Office provides several hundred maps for various technology fields since 1997 [39].

Exemplarily, Ouyang and Weng [57] develop an approach for new product design based on patent data in mechanical engineering processes. Recently, Lee, Han and Sohn [47] predict patterns of technology convergence using big data information in triadic patents. Altuntas, Dereli and Kusiak [1] develop a new method to predict technological success based on patents. Also, researchers found relations to social networks and marketing [43]. In technical niches such as carbon nanotube field emissions, Chang, Wu and Leu [14] reveal the patenting activities and technology clusters in an emerging field.

\section{Method}

To build a systematic analysis of gamification related patents, we applied a three-stage process. This approach is similar to classical literature reviews.

(1) Identification - we identified all patents by searching in publicly available databases with the specific terms "gamification", "gamified", "gamify" and "gamif*" (* indicates an open ending). Each of these terms has been found in either the abstract, description, title or claim ( $s$ ) of the patent document [33]. To capture the relevant databases, we have searched within European Patent Office (EPO) and likewise the United States Patent and Trademark Office (USTPO) [33]. These sources are regarded as significant and relevant [56]. To crosscheck our data, we used Google Patent Search to contemplate the analysis. We left out 9 patent documents which were not available in English.

(2) Content-based analysis - the previously identified patents have been downloaded and saved as PDF. About $80 \%$ of the patent document are made up of technologically relevant information [67]. To handle the amount of raw data, we use Leximancer (info.leximancer.com), a professional text mining software that enables an in-depth structural analysis. The raw text is systematically read and the software finds concepts and sets it into relation. The method is increasingly applied to visually illustrate the extracted (text) information [e.g. 16, 30, 43]. Especially for patents, such analyses are useful as the technical and legal information is complex and difficult to understand for nonprofessionals. Within the analysis, human biases and subjectivity can be excluded as the concepts emerge automatically with minimal manual and human intervention. Compared to other tools (e.g. NVivo) no rules or codes are being pre-defined in the analysis, resulting in sounded reliability and validity [16]. The basic behind these semantic evaluations is that "words tend to correlate with each other over a certain range within the text" as Beeferman, Berger and Lafferty [4] find. Smith and Humphreys [64] have highlighted the working method of Leximancer: the software selects a ranked listing of terms on the basis of word frequency and co-occurrence (ranking). These identified terms undergo a bootstrapping thesaurus that develops a batch of classifications of the text by gradually expanding around the ranking [64]. These weighted term classifiers are semantically developed concepts. Every three sentences the words are arranged by these concepts, resulting in a concept index matrix which is finally mapped by a clustering algorithm [64]. The concept-mapping algorithm itself has its foundation in the spring-force model of the manybody problem [see 13, 16]. To sum up, the 
software employs two stages of extraction performed sequentially which is a semantic and a relational extraction based on co-occurrence records [64].

(3) Clustering - based on the software results from the raw data, ranking, matrix, concept map a semantic network is built to cluster them into themes. The result is a numerical model based on the terminology of a "complex network system" [64]. Such network represents highly connected concepts and show the overall content on a hierarchical level. The Leximancer software helps to make the analyst aware of the higher meaning within the data and therewith less fixed on a particular maybe atypical evidence [64]. Such clustering is ideal for analyzing large amounts of technical descriptions into higher meaning concepts for emerging technologies. Out of this information, we develop the Technical Gamification Framework. The framework is intended to highlight the aggregated fundamentals in patents. This is a decisive difference to other frameworks, which classify with larger human biases on less objective data [e.g. 11] especially in such an emerging field as gamification. For the specific analysis of game elements, we have relied on Leximancer's "user defined concepts" and have accordingly created the three relevant pyramid elements [69] for the analysis. For example, "mechanics" consists of 'challenges', 'competition' and so forth [69].

\section{Analysis and results}

To begin, we illustrate recent statistics that have been retrieved in the data collection. In our search through the patent databases, we have gathered 134 patents. In initial search for gamification related patents [33] around 70 patents have been found in this very area. This results in an increase of nearly $90 \%$ in about 6 months. One must remember that every patent is by its definition unique [25], hence the invention is the first of its kind. In order to carry out the analysis, Leximancer works with stop words, so terms low in meaning (e.g. "the", "and", "for") are being omitted. We have additionally set that the word variations count to the same concept (exemplarily "device" and "devices"). We analyze the entire text of the available patent documents.

To continue, we highlight the concepts which emerged out of the raw data. We have structured the concepts and ranked them for the entire patent documents highlighting the top ten concepts (absolute count, relative relevance in percent): data (12580, $100 \%)$, user $(10271,82 \%)$, embodiment $(6797,54 \%)$, device $(6394,51 \%)$ computing $(5865,47 \%)$, use $(5810,46 \%)$, information $(4682,37 \%)$, present $(4630$,
$37 \%)$, invention $(3943,31 \%)$, associated $(3725,30 \%)$. Due to length restrictions, the full list can be found in the in the following link ${ }^{1}$. As explained in the method section, the themes are built upon these highly connected concepts via a semantic network. To get a feeling which concepts emerge into which themes, Table 1 highlights underlying structure for each of the themes (top five): device, data, use, user and game.

Table 1: Themes, connectivity and concepts identified by Leximancer

\begin{tabular}{|l|c|l|}
\hline Theme & Connectivity & Concepts \\
\hline device & $100 \%$ & $\begin{array}{l}\text { communication, storage, } \\
\text { processing, program, software, } \\
\text { mobile, memory, media, } \\
\text { component, digital, signal }\end{array}$ \\
\hline data & $87 \%$ & $\begin{array}{l}\text { data, information, network, } \\
\text { application, access, module, } \\
\text { performance, service, location, } \\
\text { database }\end{array}$ \\
\hline use & $53 \%$ & $\begin{array}{l}\text { use, display, limited, augmented, } \\
\text { reality, control, view, physical, } \\
\text { screen, video, context }\end{array}$ \\
\hline user & $45 \%$ & $\begin{array}{l}\text { user, associated, content, customer, } \\
\text { social, message, available }\end{array}$ \\
game & & $\begin{array}{l}\text { gamification, action, points, } \\
\text { player, experience, play }\end{array}$ \\
\hline & $53 \%$ & \\
\hline & &
\end{tabular}

The connectivity measure also in Table 1 shows the following connectedness: device $(100 \%)$, data $(87 \%)$, use $(53 \%)$, user $(45 \%)$ and game $(41 \%)$. All the above-mentioned information emerges in Figure 3, which shows the entire patent document based on the in depth text analysis in its thematic content.

The result is a "natural" concept map highlighting the themes and its interrelation with minimal manual intervention based on raw patent data. The importance of each theme is based the color of the circles, so called heat maps. Red indicates important whereas blue/green show less important themes. The size of the circles indicates importance based on word count. As highlighted above five major themes emerge out of the entire patent document in Figure 3: device, data, use, user and game. 


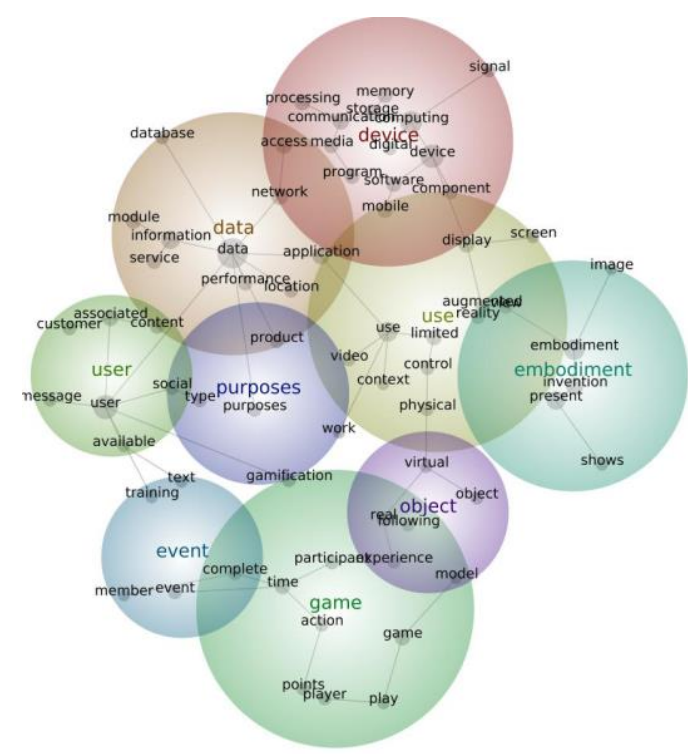

Figure 3. Leximancer results

Further we elaborate the analysis on the specific game elements that are relevant for gamification. Werbach and Hunter [69] identified the game elements hierarchy/pyramid. Therein, the fundamental drivers of gamification were defined (p. 82): "dynamics" ("big-picture of the gamified system that you have to consider and manage but which can never directly enter into the game"), "mechanics" ("processes that drive the action forward and generate player engagement") and "components" ("specific instantiations of mechanics and dynamics") [69]. Each of these three elements stands for a certain level of abstraction. We advance in a second analysis by analyzing these predefined concepts within patents. Therewith, we can highlight which known concepts and elements from gamification are implemented. As explained in the methods section, we have taken all three elements and its corresponding sub-elements [69] to make up the game element analysis in Figure 4 in a network map. A cloud map has also been created and can be found in the additional analysis document (see Footnote 1).

The following concepts and numbers have been retrieved in the second analysis (absolute count, relative relevance in percent): user $(11273,100 \%)$, data $(10171,90 \%)$, mechanics $(8856,79 \%)$, system $(8753,78 \%)$ method $(7029,62 \%)$, device (6978, $62 \%)$, computer $(6509,58 \%)$, components (5877, $52 \%)$, application $(4128,37 \%)$ and process $(3908$, $35 \%)$. Even though we specifically edited the "dynamics" element from Werbach and Hunter [69], the concepts itself showed lower relevance within the patents $(1626,14 \%)$. "Mechanics" and "components" [69] are thus relevant within patents. In all, the discovered patterns are different to the previous extracted information as several different concepts emerged: "system", "method", "computer", "application" and "process". Figure 3 and 4 are additionally available in large for a better readability in the additional file (see Footnote 1).

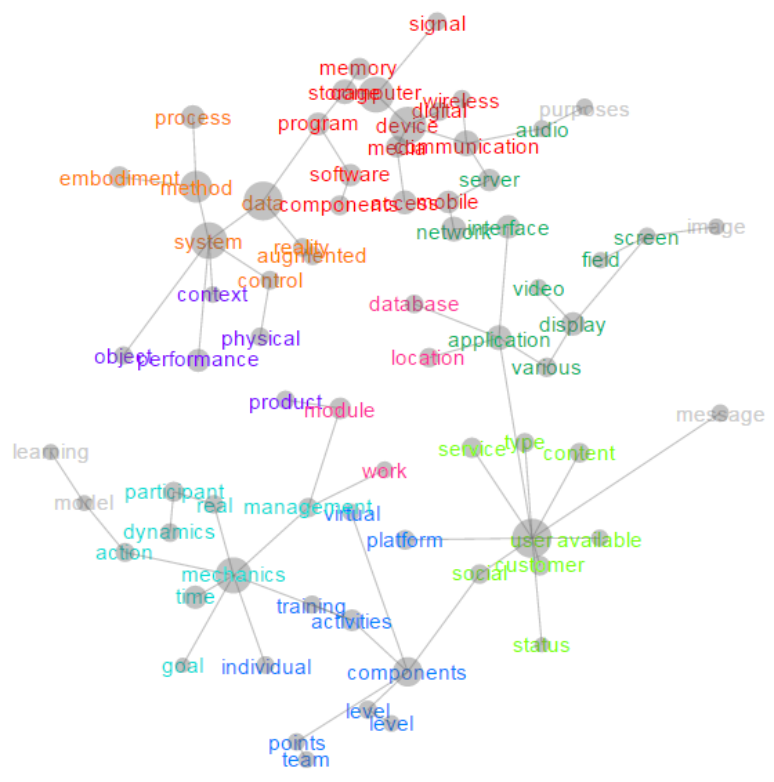

Figure 4. Leximancer results with game elements

\section{Discussion}

\subsection{Identifying the framework}

In this paper we analyze the content of international patent documents which relate to gamification. Based on the underlying raw data, namely the text of all 134 patents in two analyses, we highlight dominant concepts and its relations. Interestingly, patents are real indicators of future product releases, revealing precise technical information long before inventions reach the marketplace [66]. A patent is by its definition a novelty and secures a certain technology for up to 20 years. Considering this as the underlying data basis, the information gathered and analyzed in this paper can be informative for future products/ as innovations new to markets are often protected by patents [3].

The following results itself need to be understood according to its underlying original purpose, which is the securitization of precise technical information. The text, when the inventions are filed at the patent office, is usually written by professionals with severe technical and legal knowledge. There is usually a difference between a possible future product and its underlying proprietary technology. An example for the differences in the obvious use and underlying patent would be Apple's iPhone "slide to unlock" patent: intuitive to use, but technically difficult to describe accurately. The same logic applies for gamification related patents. To bridge this gap, we have taken an approach to overcome those drawbacks and provide visual thematic guidance. The information gathered from Leximancer can be interpreted as underlying technical conditions for the application of gamification within systems, devices and so forth. The outcome is therefore different to the 
usual design and incentive related aspects of gamification, as well as the already familiar fields of health, sports, marketing and so forth. The fact that such "technology" perspective is less visible compared to other elements in game design has been clearly elaborated by Schell [61].

Hence, the above-described findings do highlight another, very relevant technical side of gamification. The results need to be interpreted in a way that gamification is herein applied as aspect of a technical functionality within an entire system or device, producing and providing data and being used offline and online. Visualizing concepts and maps of purely technical information helps to understand the underlying functionalities [39]. Therefore, we have built and introduce the "Technical Gamification Framework" in Figure 5 based on the results from the Leximancer software. The framework identifies the technical foundations of gamification in proprietary innovation. For the following analyses, we have taken left out "use" as it may not be logically connected due its meaning (however it is no stopword or a variation). Above, the "use" category is then applied and utilized in the "situative components" of the framework.

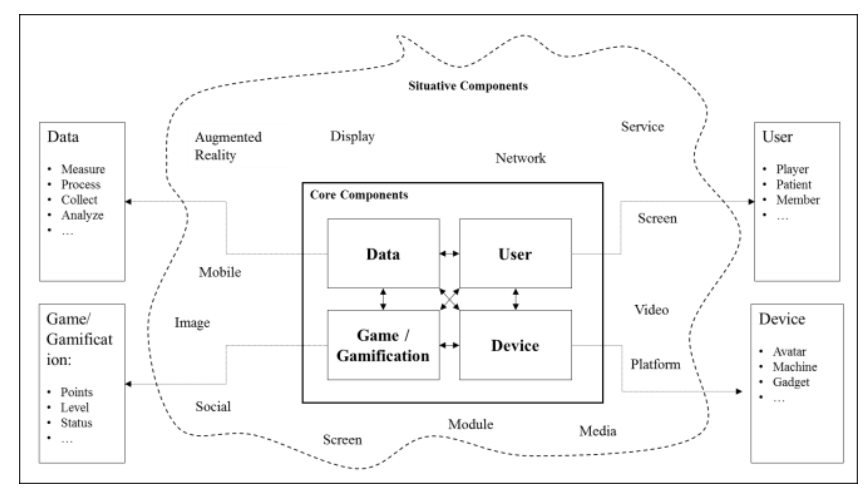

Figure 5. “Technical Gamification Framework"

Based on the underlying data, we propose that a large part of all patented gamification related patents can be traced back to these technical fundamentals. This is logically a status quo, as many more patents will likely be introduced in the years to come. Within the next paragraphs, we deep dive into the content to support the framework by concrete examples out of specific patents. Each of these core components are likely to be incorporated in future products. Basically, the framework is divided into two basic layers: the core components and secondly, the situative components.

(1) Core components are a central element to most of the gamification related patents. They have been found most often within the data and they show the highest thematic connectivity. These four core components are all mutually linked to each other and consist of data, user, device and game/gamification. For each of the core components several backgrounds, descriptions and specific patents emerge.
- "Data" represents the largest set of keywords out of the all the patents analyzed. The term has been found about 12.000 times in the text indicating major importance and centrality. Within patents and its underlying technology data/information is gathered, analyzed, processed, stored and utilized. Data is one of the most central aspects in the framework as any technical coordination within in application depends on the usage of information. An example is "Enterprise gamification system for awarding employee performance" (Patent: US 8768751 B 2 by SAP AG), where specifically a method for a data apparatus is patented that receives and processes user generated gamification data. Likewise, the user of the application is being described purely by its data processing behavior for the specific business software.

- The actual "user" of gamification related patents suggests an active role / human participation. Most often gamification is used to increase to increase human participation and engagement [20]. This is also the case for proprietary innovation related to gamification. The term "user" has been found about 10.000 times within the text analysis. A patented example is "Hand hygiene use and tracking in the clinical setting via wearable computers" (US 20150127365A1). The patent covers a computer-implemented method for monitoring hand hygiene to reduce hospital-acquired infections by patients and medical staff. Both the initiation, completion is tracked with a detected location and time parameter of a user via a head mounted device or augmented reality glasses. Therewith, the patients and medical staff are motivated and tracked to increase hygiene in hospitals.

- Another core component is "device". Gamification and its applications are not exclusively used in online environments. Hence, within the patents there are many avatars, machines or gadgets. A device is executing a certain application, which can be e.g. found in "Enhancing user retention and engagement via targeted gamification" (Patent: US 20160012679A1 by Mobile Media Partners, Inc.). The device plays a pivotal role in the regulation and controlling of the entire system. Such devices are increasingly important as gamification emerges in various disciplines as suggested in chapter 2.1 .

- Finally, there is a game/gamification element as a core component within the patents. This element is a logical component as the patents are searched with exactly this precondition. This core component often incorporates certain game rules or game logics. Often these rules act upon 
certain actions and trigger consequent, gamebased action. Hereby an example is "Gamification for Enterprise Architectures" from SAP AG (US 20140051506A1). Gamification rules are stored in a gamification repository, where predefined rules are externally deployed or the rules are calculated independently by the system ("rule management system"). Above, actions between the system and the player and other rules are also auto generated.

(2) Situative components vary and depend on the specific context where the application or a certain technology will be used (e.g. in sports or education). Authors have also highlighted the different domains of gamification [e.g. 28, 62]. Hence, this has often been a central element of their paper to argue about the specific domains where gamification takes place. Here, the situative components / contexts are differentiated to the core components. In our framework we have exemplarily taken different technology components as e.g. "augmented reality" or "mobile". The dashed line also indicates the variability of application areas. Hence, the displayed elements in Figure 5 do not represent a full list as the application areas are vast and not representable due to page restrictions. Many of them can be found in the additional documents highlighting the full list of concepts within the raw text.

Our framework deep dives into a previously underrepresented area of research focusing on the technical background of gamification. To compare our interdisciplinary study to others, we have to go into different fields likewise. Previous papers in the area of patent analysis with the use of text mining techniques also researched technical niches [e.g. 1, 14, 43] and used similar methods of analysis. Several methods for patent forecasting in various domains have been developed [see 1,46] due to a growing interest [40, 45]. Yet, within the area of gamification none of the studies developed a coherent framework based on state-of-the-art technological information.

Above, previous frameworks related to gamification as e.g. from Nah, Telaprolu, Rallapalli and Venkata [55] or from Simões, Redondo and Vilas [63] have not discussed the technical side. Also, previous game-design elements and motives connected to gamification as e.g. from Blohm and Leimeister [9] did not deep dive into the technical domain. Bui, Veit and Webster [11] mentioned "technologies" as a category and a sub-category of "software" (enterprise software, game software, learning software) or "platform" (app, website) within their analysis. Hence, Ralph and Monu [58] specifically highlighted "technology" and refer to it as "tools and systems used to implement or deliver the gameplay" (p. 1). Based on the technical fundamentals, we see our framework also as an enabler for the understanding of gamification in various technical fields. Ralph and Monu [58] also highlight concepts and elements found similarly in our raw text analysis as e.g. "game console" "motion sensor" or "monitor". Also, patterns of gamification domains have been researched [43]. Finally, within game design, Schell [61] also finds that "technology" is an ample part of any game play design as it enables applications. Above, Schell [61] highlights that technology is less visible than e.g. game "aesthetics". This is also similar to the analysis of patents as the functioning is rather complex and difficult to observe with limited visibility [60].

\subsection{Additional game analysis}

As this paper centers around game/gamification, another analysis is being created to highlight its relation within patents. The three fundamental game elements from Werbach and Hunter [69] have been found in the patent data. However, only "mechanics" and "components" are highly connected, "dynamics" are rather less relevant. "Mechanics" and "components" represent a higher level of abstraction [69], a finding which can be confirmed in the patent documents. Above, the network map shows that "mechanics" and "components" are closely connected to the "user". Interestingly, even when using a predefined coding in Leximancer, the main terms of the natural analysis and the logical framework persist, namely data, device and user. Likely, the "game" element from the framework is now splitted in "mechanics" and "components". Above, learning and performance are relevant and closely connected. Werbach and Hunter [69] "dynamics" element is rather less relevant in the patent data. This is somewhat logical, as "dynamics" are defined (p. 82) as "aspects of the gamified system that you have to consider and manage but which you can never directly enter into the game" [69]. Technical information can simply not integrate such information as the variability in its meaning is too broad. Patent data must be "highly-specific technical or scientific jargon" [10] to be implemented and finally protected.

Taken together, these underlying technologies will be a major driver for the future products in this field. Our framework covers the technical foundations of gamification related patents. Therefore, we propose that the future gamification frameworks should be elaborated to include these technical fundamental considerations.

\subsection{Conclusion, Limitations and Future Research}

Patents are the predominant form of technological innovation and are a bet that a technology may become economically relevant [21]. Gamification related patents occur in various technology classes [33]. Our study is an attempt to map and monitor how current gamification is applied and interconnected in proprietary knowledge. Understanding its foundations 
is essentially strategic to keep up with competition both for industry leaders as well as new technology ventures. Our additional game elements analysis based on Werbach and Hunter [69] also shows that the fundamental gamification elements can be traced in proprietary innovation.

We contribute to the understanding of gamification and its foundation in IP in various ways. First, grounded on the nature of the evidence-based and future directed data, the technical foundations of gamification related patents are analyzed systematically. We can thereby highlight dominant patterns of gamification in proprietary innovation. This study follows the ongoing trend and growing interest in applying text mining techniques in different research areas [45], especially in technical niches [5] with the use of patent data [14, 15, 57]. Previous patent studies in gamification relied mainly on standard information [33]. The results can be strategically decisive for monitoring future products/product development with gamification. To date, it has been unclear what kind of proprietary knowledge actually exists within this field.

Secondly, since the field of gamification is fragmented in its applications, we are able to integrate and connect important concepts. Our analysis and its implications are relevant for the understanding of technical functionalities with gamification. Technologies can either be a new combination of extant technology or completely novel technologies where applications create major paradigm shifts [41, 68 ]. From the analysis of this paper we conclude that gamification is rather within existing technologies (as a central core component with e.g. specific devices or data-related) and not a standalone technology. Hence, since not all applications just become better per se through a gameful design [28], the integration of gamification into a framework is an essential step forward for our holistic understanding.

Finally, it is decisive to reflect that any action in IP is essentially to securitize precise technical information to withstand competition [24]. Usually, it is extensively used as an instrument to exclude rivals and build markets. This paper's technological perspective will advance what we currently understand and what R\&D managers can feasibly take away for their technological planning. Patented gamification related knowledge may be a source for innovation and competitive advantage for firms. The strategic positioning of firms can be decisively improved when knowing what competitors around the world are actually patenting in this very domain.

Yet, we have to discuss a number of our study's limitations. First, we analyze patents that originate from different patent offices (USPTO and EPO). These patent offices do have differences concerning patent law, standards and application processes [e.g. 22] which may influence the type of knowledge that can be patented. An example would be less restricted patentability of software and business methods in the US [19]. Secondly, the search terms for our analysis only relate to gamification. As gamification is an incentive-driven mechanism, previous patents that may have gamification-like elements cannot be traced (and included) due to specification problems. Hence, technology is constantly evolving and the current analysis pictures state-of-the-art results. How gamification related technology within international patent documents will continue is a research task to be repeated in order to track the technological advancement. Future frameworks may take a different perspective based on the underlying (future) technology.

Future research should continue to investigate gamification related patents in the innovation landscape, specifically with patent data. An example could be changing patterns on a time scale to observe differences in the importance of subthemes, i.e. rising applications only in specific areas from time to time. Another interesting topic for further research would be a knowledge diffusion via an in depth citation network analysis (also based on quantifiable and objective criteria). An example could be which gamification related patents do build their novelty upon which prior proprietary knowledge as they essentially need to cite them [e.g. 37].

\section{References}

[1] Altuntas, S., Dereli, T., and Kusiak, A., "Forecasting Technology Success Based on Patent Data", Technological Forecasting and Social Change, 96(2015, pp. 202-214.

[2] Aoki, R., and Schiff, A., "Promoting Access to Intellectual Property: Patent Pools, Copyright Collectives, and Clearinghouses", R\&D Management, 38(2), 2008, pp. 189-204.

[3] Battisti, G., Gallego, J., Rubalcaba, L., and Windrum, P., "Open Innovation in Services: Knowledge Sources, Intellectual Property Rights and Internationalization", Economics of Innovation and new technologyahead-of-print), 2014, pp. 1-25.

[4] Beeferman, D., Berger, A., and Lafferty, J., "A Model of Lexical Attraction and Repulsion", Proceedings of the eighth conference on European chapter of the Association for Computational Linguistics, 1997, pp. 373-380.

[5] Berkowitz, L., "Getting the Most from Your Patents", ResearchTechnology Management, 36(2), 1993, pp. 26-31.

[6] Bernard, A.B., and Jones, C.I., "Technology and Convergence", The Economic Journal, 106(437), 1996, pp. 1037-1044.

[7] Bhattacharya, S., and Khan, M.D.T.R., "Monitoring Technology Trends through Patent Analysis: A Case Study of Thin Film", Research Evaluation, 10(1), 2001, pp. 33-45.

[8] Blind, K., Edler, J., Frietsch, R., and Schmoch, U., "Motives to Patent: Empirical Evidence from Germany", Research Policy, 35(5), 2006, pp. 655-672.

[9] Blohm, I., and Leimeister, J.M., "Gamification: Design of ItBased Enhancing Services for Motivational Support and Behavioral Change", Business \& Information Systems Engineering (BISE), 5(4), 2013, pp. 275-278. 
[10] Breschi, S., and Lissoni, F., "Knowledge Networks from Patent Data": Handbook of Quantitative Science and Technology Research, Springer, 2004, pp. 613-643.

[11] Bui, A., Veit, D., and Webster, J., "Gamification - a Novel Phenomenon or a New Wrapping for Existing Concepts?"2015

[12] Burk, D.L., "The Role of Patent Law in Knowledge Codification", Berkeley Technology Law Journal, 23(3), 2008, pp 1009-1034

[13] Chalmers, M., and Chitson, P., "Bead: Explorations in Information Visualization", Proceedings of the 15th annual international ACM SIGIR conference on Research and development in information retrieval, 1992, pp. 330-337.

[14] Chang, P.-L., Wu, C.-C., and Leu, H.-J., "Using Patent Analyses to Monitor the Technological Trends in an Emerging Field of Technology: A Case of Carbon Nanotube Field Emission Display", Scientometrics, 82(1), 2010, pp. 5-19.

[15] Chang, S.W., Trappey, C.V., Trappey, A.J., and Wu, S.C.-Y., "Forecasting Dental Implant Technologies Using Patent Analysis", Proceedings of PICMET'14 Conference: Portland International Center for Management of Engineering and Technology; Infrastructure and Service Integration, 2014, pp. 1483-1491.

[16] Cretchley, J., Gallois, C., Chenery, H., and Smith, A. "Conversations between Carers and People with Schizophrenia: A Qualitative Analysis Using Leximancer", Qualitative Health Research, 20(12), 2010, pp. 1611-1628.

[17] Cruz-Cázares, C., Bayona-Sáez, C., and García-Marco, T., "You Can't Manage Right What You Can't Measure Well: Technological Innovation Efficiency", Research Policy, 42(6-7), 2013, pp. 1239-1250

[18] Davis, R., "Organizing and Conducting Technologica Forecasting in a Consumer Goods Firm", A Practical Guide to Technological Forecasting. Englewood Cliffs, NJ: Prentice Hall, 1973, pp. 601-618

[19] De La Potterie, B.V.P., "The Quality Factor in Patent Systems", Industrial and Corporate Change, 20(6), 2011, pp. 1755-1793.

[20] Deterding, S., Khaled, R., Nacke, L.E., and Dixon, D. "Gamification: Toward a Definition", CHI 2011 Gamification Workshop Proceedings, 2011, pp. 12-15.

[21] Eusebi, C.A., and Silberglitt, R., "Identification and Analysis of Technology Emergence Using Patent Classification", 2014,

[22] Graham, S., Hall, B.H., Harhoff, D., and Mowery, D.C. "Patent Quality Control: A Comparison of Us Patent Reexaminations and European Patent Oppositions", National Bureau of Economic Research Working Paper Series, 2002, pp. 146.

[23] Griliches, Z., "Patent Statistics as Economic Indicators: A Survey", Journal of Economic Literature, 28(4), 1990, pp. 16611707.

[24] Grimpe, C., and Hussinger, K., "Rent Appropriation and Competitor Blocking: The Two Faces of Technology Acquisition ", DRUID Conference, 2008,

[25] Hagiu, A., and Yoffie, D., "Intermediaries for the Ip Market", Harvard Business School Working Paper, 12(023), 2011, pp. 1-30.

[26] Hakulinen, L., Auvinen, T., and Korhonen, A., "Empirical Study on the Effect of Achievement Badges in Trakla2 Online
Learning Environment", IEEE Xplore - Learning and Teaching in Computing and Engineering (LaTiCE), 2013, pp. 47-54

[27] Hall, B.H., Jaffe, A.B., and Trajtenberg, M., "Market Value and Patent Citations: A First Look", NBER Working Paper No. 7741, 2000, pp. 1-64

[28] Hamari, J., Koivisto, J., and Sarsa, H., "Does Gamification Work?--a Literature Review of Empirical Studies on Gamification", 47th Hawaii International Conference on System Sciences (HICSS), 2014, pp. 3025-3034

[29] Hamari, J., and Koivisto, J., "Why Do People Use Gamification Services?", International Journal of Information Management, 35(4), 2015, pp. 419-431

[30] Hansson, T., Carey, G., and Kjartansson, R., "A Multiple Software Approach to Understanding Values", Journal of Beliefs \& Values, 31(3), 2010, pp. 283-298

[31] Hirschey, M., and Richardson, V.J., "Valuation Effects of Patent Quality: A Comparison for Japanese and Us Firms", PacificBasin Finance Journal, 9(1), 2001, pp. 65-82.

[32] Hirshleifer, D., Hsu, P.-H., and Li, D., "Innovative Efficiency and Stock Returns", Journal of Financial Economics, 107(3), 2013, pp. 632-654.

[33] Höflinger, P., and Zimmerling, E., "Monitoring Gamification in International Patent Documents: Technology Classes, Firms and Preliminary Value Indicators", 49th Hawaii International Conference on System Sciences (HICSS), 2016, pp. 1319-1327.

[34] Huotari, K., and Hamari, J., "'Gamification" from the Perspective of Service Marketing", Proceedings CHI Workshop Gamification, 2011, pp. 1-5.

[35] Huotari, K., and Hamari, J., "A Definition for Gamification: Anchoring Gamification in the Service Marketing Literature", Electronic Markets, 2016, pp. 1-11

[36] Iwai, K., "A Contribution to the Evolutionary Theory of Innovation, Imitation and Growth", Journal of Economic Behavior \& Organization, 43(2), 2000, pp. 167-198.

[37] Jaffe, A.B., Trajtenberg, M., and Henderson, R., "Geographic Localization of Knowledge Spillovers as Evidenced by Patent Citations", The quarterly journal of Economics, 1993, pp. 577-598.

[38] Kim, J., and Lee, S., "Patent Databases for Innovation Studies: A Comparative Analysis of Uspto, Epo, Jpo and Kipo", Technological Forecasting and Social Change, 92(2015, pp. 332345 .

[39] Kim, Y.G., Suh, J.H., and Park, S.C., "Visualization of Patent Analysis for Emerging Technology", Expert Systems with Applications, 34(3), 2008, pp. 1804-1812.

[40] Kostoff, R.N., Toothman, D.R., Eberhart, H.J., and Humenik, J.A., "Text Mining Using Database Tomography and Bibliometrics: A Review", Technological Forecasting and Social Change, 68(3), 2001, pp. 223-253.

[41] Kostoff, R.N., Boylan, R., and Simons, G.R., "Disruptive Technology Roadmaps", Technological Forecasting and Social Change, 71(1), 2004, pp. 141-159.

[42] Kuznets, S., "Inventive Activity: Problems of Definition and Measurement": The Rate and Direction of Inventive Activity: Economic and Social Factors, Princeton University Press, 1962, pp. 19-52. 
[43] Lai, N., Höflinger, P., and Zimmerling, E., The Science and Technology of Gamification: Domains and Forms of Gamification in Research and Practice., Technische Universität München, 2015.

[44] Lee, C., Song, B., and Park, Y., "Design of Convergent Product Concepts Based on Functionality: An Association Rule Mining and Decision Tree Approach", Expert Systems with Applications, 39(10), 2012, pp. 9534-9542.

[45] Lee, C., Kang, B., and Shin, J., "Novelty-Focused Patent Mapping for Technology Opportunity Analysis", Technological Forecasting and Social Change, 90(2015, pp. 355-365.

[46] Lee, S., Yoon, B., and Park, Y., "An Approach to Discovering New Technology Opportunities: Keyword-Based Patent Map Approach", Technovation, 29(6-7), 2009, pp. 481-497.

[47] Lee, W.S., Han, E.J., and Sohn, S.Y., "Predicting the Pattern of Technology Convergence Using Big-Data Technology on LargeScale Triadic Patents", Technological Forecasting and Social Change, 100(2015, pp. 317-329.

[48] Losiewicz, P., Oard, D.W., and Kostoff, R.N., "Textual Data Mining to Support Science and Technology Management", Journal of Intelligent Information Systems, 15(2), 2000, pp. 99-119.

[49] Martino, J.P., Technological Forecasting for Decision Making, McGraw-Hill, Inc., 1993.

[50] Mccallum, S., "Gamification and Serious Games for Personalized Health", Stud Health Technol Inform, 177(2012, pp. 85-96.

[51] Merges, R.P., "Commercial Success and Patent Standards: Economic Perspectives on Innovation", California Law Review, 1988, pp. 803-876

[52] Mitchell, G.R., "New Approaches for the Strategic Management of Technology", Technology in Society, 7(2), 1985 , pp. 227-239.

[53] Moehrle, M.G., Walter, L., Geritz, A., and Müller, S., "PatentBased Inventor Profiles as a Basis for Human Resource Decisions in Research and Development", R\&D Management, 35(5), 2005, pp. 513-524

[54] Mogee, M.E., "Using Patent Data for Technology Analysis and Planning", Research Technology Management, 34(4), 1991, pp. 43

[55] Nah, F.F.-H., Telaprolu, V.R., Rallapalli, S., and Venkata, P.R., "Gamification of Education Using Computer Games", International Conference on Human Interface and the Management of Information, 2013, pp. 99-107.

[56] Nikulainen, T., Pajarinen, M., and Palmberg, C., "Patents and Technological Change: A Review with Focus on the Fepoci Database", 984(2005, pp. 1-33.

[57] Ouyang, K., and Weng, C.S., "A New Comprehensive Patent Analysis Approach for New Product Design in Mechanical Engineering", Technological Forecasting and Social Change, 78(7), 2011, pp. 1183-1199.

[58] Ralph, P., and Monu, K., Mtda+ N-a Working Theory of Game Design, First Person Scholar, 2014

[59] Richards, C., Thompson, C.W., and Graham, N., "Beyond Designing for Motivation: The Importance of Context in Gamification", Proceedings of the first ACM SIGCHI annual
226

[60] Rindova, V.P., Williamson, I.O., Petkova, A.P., and Sever, J.M., "Being Good or Being Known: An Empirical Examination of the Dimensions, Antecedents, and Consequences of Organizational Reputation", Academy of Management Journal, 48(6), 2005, pp. 1033-1049.

[61] Schell, J., The Art of Game Design: A Book of Lenses, CRC Press, 2014.

[62] Seaborn, K., and Fels, D.I., "Gamification in Theory and Action: A Survey", International Journal of Human-Computer Studies, 74(2015, pp. 14-31.

[63] Simões, J., Redondo, R.D., and Vilas, A.F., "A Social Gamification Framework for a K-6 Learning Platform", Computers in Human Behavior, 29(2), 2013, pp. 345-353.

[64] Smith, A.E., and Humphreys, M.S., "Evaluation of Unsupervised Semantic Mapping of Natural Language with Leximancer Concept Mapping", Behavior Research Methods, 38(2), 2006, pp. 262-279

[65] Smith, H., "Automation of Patent Classification", World Patent Information, 24(4), 2002, pp. 269-271.

[66] Tang, J., Wang, B., Yang, Y., Hu, P., Zhao, Y., Yan, X., Gao, B., Huang, M., Xu, P., and Li, W., "Patentminer: Topic-Driven Patent Analysis and Mining", Proceedings of the 18th ACM SIGKDD International Conference on Knowledge Discovery and Data Mining, 2012, pp. 1366-1374.

[67] Teichert, T., and Mittermayer, M.-A., "Text Mining for Technology Monitoring", IEEE International Engineering Management Conference, 2002, pp. 596-601.

[68] Walsh, S.T., and Linton, J.D., "Infrastructure for Emergent Industries Based on Discontinuous Innovations", Engineering Management Journal, 12(2), 2000, pp. 23-32.

[69] Werbach, K., and Hunter, D., For the Win: How Game Thinking Can Revolutionize Your Business, Wharton Digital Press, 2012.

[70] Westphal, C., and Blaxton, T., Data Mining Solutions: Methods and Tools for Solving Real-World Problems, 1998.

[71] Yoon, B., and Park, Y., "A Text-Mining-Based Patent Network: Analytical Tool for High-Technology Trend", The Journal of High Technology Management Research, 15(1), 2004, pp. $37-50$.

[72] Yoon, J., and Kim, K., "An Analysis of Property-Function Based Patent Networks for Strategic R\&D Planning in Fast-Moving Industries: The Case of Silicon-Based Thin Film Solar Cells", Expert Systems with Applications, 39(9), 2012, pp. 7709-7717.

[73] Zichermann, G., and Cunningham, C., Gamification by Design: Implementing Game Mechanics in Web and Mobile Apps, O'Reilly Media, Inc., 2011.

[74] Zimmerling, E., Höflinger, P.J., Sandner, G.P., and Welpe, M.I., "A System Framework for Gamified Cost Engineering", Information Systems Frontiers, 2016, pp. 1-22. 